\title{
Planar Dual-Band Monopole Antenna with an Extended Ground Plane for WLAN Applications
}

\author{
Ayman S. Al-Zayed and V. A. Shameena \\ Department of Electrical Engineering, Kuwait University, P.O. Box 5969, Al-Safat, 13060 Kuwait City, Kuwait \\ Correspondence should be addressed to Ayman S. Al-Zayed; ayman.alzayed@ku.edu.kw
}

Received 10 May 2016; Revised 6 July 2016; Accepted 26 July 2016

Academic Editor: Claudio Gennarelli

Copyright (C) 2016 A. S. Al-Zayed and V. A. Shameena. This is an open access article distributed under the Creative Commons Attribution License, which permits unrestricted use, distribution, and reproduction in any medium, provided the original work is properly cited.

\begin{abstract}
A compact planar microstrip-fed monopole antenna designed for dual-band operation is proposed for WLAN applications. The antenna is composed of a rectangular strip monopole in addition to an inverted-L parasitic element that is connected to the truncated ground plane of the microstrip feed. Besides exciting an additional band of operation, the parasitic element also improves the bandwidth of the band excited by the strip monopole. Several simulated parametric studies are conducted to investigate the effects of each geometrical parameter on the behavior of the antenna. Experimental and simulation results demonstrate that the proposed antenna covers the 2.4 and $5.8 \mathrm{GHz}$ bands utilized in WLAN. In both bands, the proposed antenna exhibits good impedance match, moderate gain (approximately $2 \mathrm{dBi}$ ), and sustainable omnidirectional-like radiation patterns in both principal planes. An equivalent circuit model of the antenna is also developed.
\end{abstract}

\section{Introduction}

The drastic growth in the demand for wireless communications necessitates an accelerated development of wireless systems and their components in terms of size, cost, bandwidth, functionality, and so forth. In that regard, antennas, which are an integral part of wireless systems, are required to be of compact size, multiband operation, and multiple polarization states, among other requirements. Printed monopoles are considered to be suitable candidates for modern wireless systems because of their ease of fabrication, size, and cost. For example, it has been demonstrated that printed monopoles can be used in WLAN (Wireless Local Area Network) applications $[1,2]$ and WiMAX (Worldwide Interoperability for Microwave Access) applications [3, 4].

In printed monopoles, implementing multiband operation, such as that required in WLAN and WiMAX applications, can be achieved by incorporating parasitic resonators to the antenna. These resonators can be attached to the radiator itself $[5,6]$ and placed on the same plane as the radiator (top of the substrate) $[7,8]$, on the plane opposite to it (bottom of the substrate) $[9,10]$, or on a combination of both $[11,12]$. First, attaching resonators to the radiating monopole creates additional current paths that result in multiband operation. An example of this can be found in [5], where two resonators have been attached to a conventional monopole creating a forkshaped antenna, resulting in a triple-band operation covering the WLAN and WiMAX bands. Multiband operation can also be achieved by loading the monopole with metamaterial resonators. This has been implemented in [6], where a strip monopole has been loaded with a CRLH (Composite Right/Left-Handed) unit cell, resulting in triple-band operation. Instead of directly connecting the resonators to the monopole radiator, parasitic resonators can be placed on the same plane as the radiator or opposite to it [7-12]. One of the well-known antennas that utilize this technique is the sleeve monopole antenna $[7,8]$. It consists of the monopole along with two coplanar shorted resonators. The configuration results in a dual-band operation that can produce a wideband performance by carefully selecting the lengths of the resonators 
[7]. Another way to utilize parasitic resonators is to place them on the bottom side of the substrate. For example, an open-ended inverted-L parasitic resonator is placed on the bottom plane of the monopole antenna presented in [9]. This resonator contributed to one of the three bands of operation of this antenna. In [10], placing a shorted parasitic resonator in the ground plane of a microstrip-fed monopole resulted in a dual-band operation, where the parasitic resonator contributed to an additional band besides that excited by the main monopole. A combination of the preceding techniques can be used to increase the number of bands operable by a monopole. For example, a modified fork-shaped monopole with two identical open-ended resonators on the bottom side has been proposed in [11] to cover three WLAN bands and the WiMAX band of operation. In [12], three parasitic resonators of different types have been incorporated in the design of a monopole antenna to achieve triple-band operation. Two of these resonators were on the top side with one being shorted and the other being open-ended. The third resonator was open-ended and placed on the bottom side of the substrate.

In this paper, a simple planar dual-band microstripfed printed monopole antenna is proposed. The antenna is basically a conventional strip monopole with a shorted inverted-L parasitic resonator connected to the truncated ground plane on the bottom side of the substrate. The antenna supports two frequency bands of 2.4 and $5.8 \mathrm{GHz}$ which are those of the WLAN. The first band $(2.4 \mathrm{GHz})$ and the second band $(5.8 \mathrm{GHz})$ are excited by the resonance of the parasitic resonator and the resonance of the strip monopole, respectively. Several simulated parametric studies are conducted to investigate the effects of the truncated grounds dimensions along with the impact of the other geometrical parameters of the antenna. The antenna design along with measured and simulated results is presented and discussed in detail in the upcoming sections.

\section{Antenna Design}

The geometry of the proposed planar dual-band monopole antenna is shown in Figure 1. The radiator of the antenna is a conventional rectangular strip monopole printed on the top side of a substrate, and it is fed by a $50 \Omega$ microstrip line. The width of the radiator $(W)$ is the same as that of the feeder, and the total length of the radiator along with the feeder is given by $(L)$. On the bottom side of the substrate, the truncated ground plane of the feeder is present with a size of $L_{\mathrm{g}} \times W_{\mathrm{g}}$. The shorted inverted-L parasitic element consists of a vertical strip of size $L_{\mathrm{p} 1} \times W_{\mathrm{p} 1}$ loaded from the top with a horizontal strip of size $\left(L_{\mathrm{p} 2}+W_{\mathrm{p} 1}\right) \times W_{\mathrm{p} 2}$. The dual-band operation of the proposed antenna can be understood by considering the contribution of each of its parts as shown in Figure 2. The main part of the antenna, shown in Figure 2(a) (Antenna A), is a conventional microstrip-fed quarter-wave monopole which contributes to the higher band of operation.

To realize the lower band, a strip is attached to the ground plane of the monopole antenna as shown in Figure 2(b) (Antenna B). This strip is considered to be a shorted parasitic resonator which is excited by the reverse current

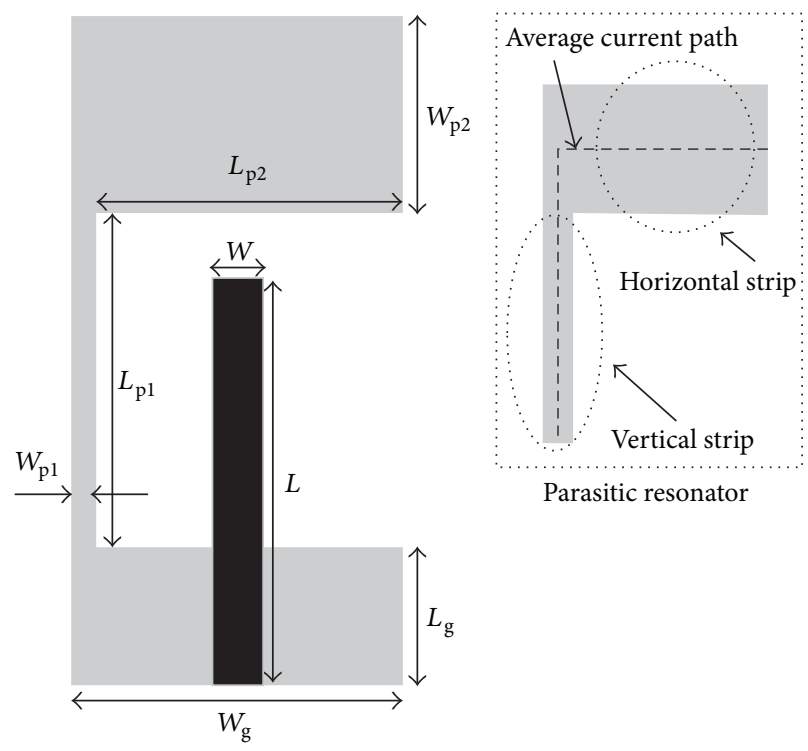

Top conductor

Bottom conductor

FIGURE 1: Geometry of the proposed dual-band monopole antenna.

TABLE 1: Dimensions of the proposed antenna.

\begin{tabular}{lc}
\hline Symbol & Value $(\mathrm{mm})$ \\
\hline$L$ & 15 \\
$L_{\mathrm{g}}$ & 6 \\
$L_{\mathrm{p} 1}$ & 12 \\
$L_{\mathrm{p} 2}$ & 8.42 \\
$W$ & 3 \\
$W_{\mathrm{g}}$ & 10 \\
$W_{\mathrm{p} 1}$ & 0.5 \\
$W_{\mathrm{p} 2}$ & 7 \\
\hline
\end{tabular}

of the microstrip feeder. The parasitic strip is then loaded with an additional horizontal strip with a different width as shown in Figure 2(c) (Antenna C) to improve the impedance matching and to further lower the resonant frequency of the operational band. The three antennas shown in Figure 2 are simulated and their reflection coefficients are displayed in Figure 3 for comparison. The simulated antennas are implemented on FR- 4 substrate with a dielectric constant of $\epsilon_{r}=4.4$ and height $h=1.6 \mathrm{~mm}$. The dimensions of the three antennas are identical and are given in Table 1.

For the monopole shown in Figure 2(a), a single resonance is observed at $6.2 \mathrm{GHz}$. As for Antenna B, two resonances are observed; the lower resonance is attributed to the shorted parasitic resonator, whereas the higher is attributed to the monopole. It can be noticed that the loading effects of the parasitic resonator resulted in a lower resonant frequency of the monopole in Antenna B. It can also be seen that the lower band is poorly matched. As for the proposed antenna (Antenna C), the two resonances are observed at $2.4 \mathrm{GHz}$ and $5.6 \mathrm{GHz}$. The top loading introduced to the ground 


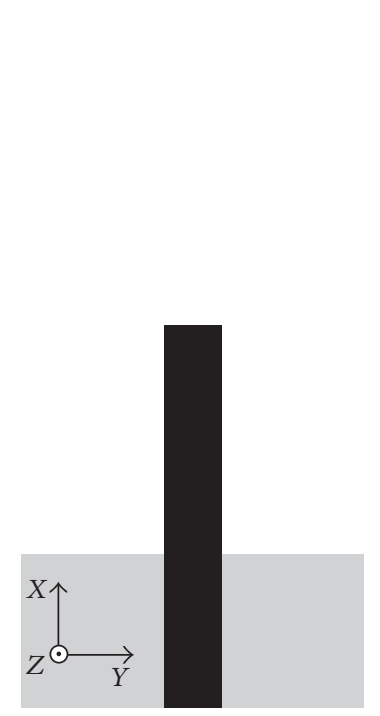

(a)

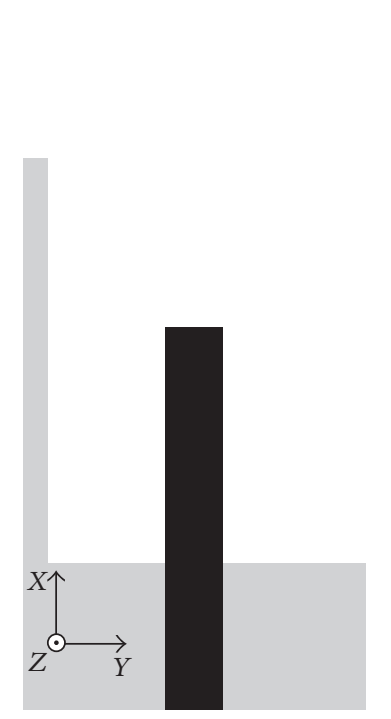

(b)

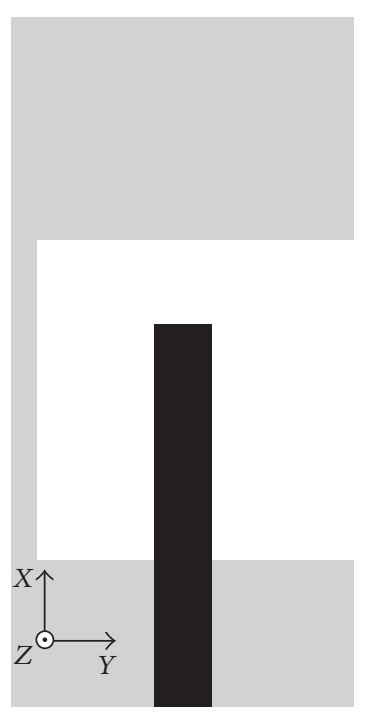

(c)

FIGURE 2: Evolution of the proposed antennas design. (a) Conventional strip monopole (Antenna A). (b) The monopole with a shorted ground plane parasitic resonator (Antenna B). (c) The proposed antenna (Antenna C).

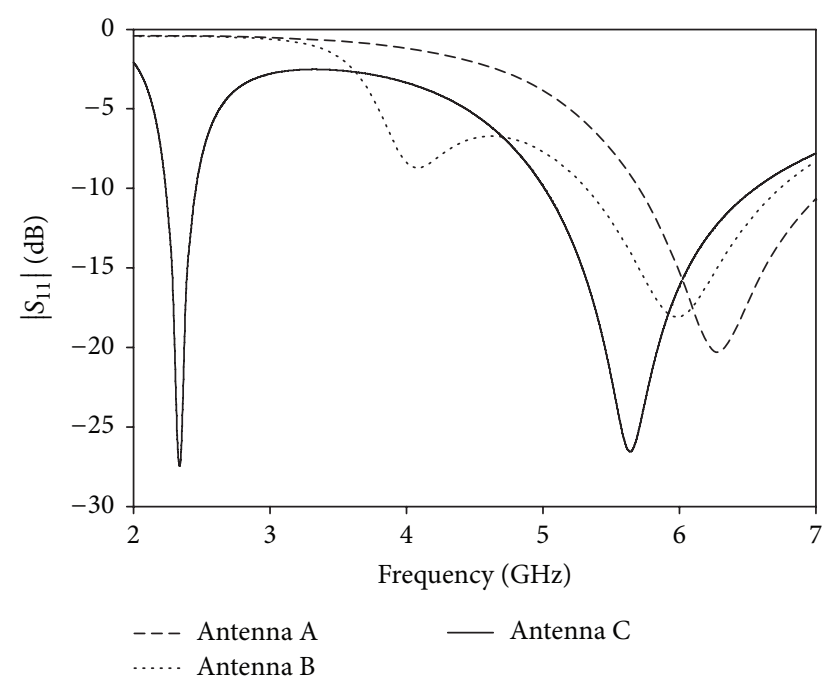

FIGURE 3: Reflection coefficients of antennas shown in Figure 2.

plane parasitic resonator led to a good matching at the lower band and lowered its resonant frequency. The higher band is further lowered due to the increased loading effects of the ground plane parasitic resonator.

The two resonant frequencies of the proposed antenna can be theoretically estimated. The frequency of the higher band (the resonance of the monopole) can be calculated using the following expression (all lengths in $\mathrm{cm}$ ) [13]:

$$
f_{\text {high }}=\frac{7.2}{\left(L_{\mathrm{m}}+W / 2 \pi\right) \times k} \mathrm{GHz}
$$

where $L_{\mathrm{m}}$ is the length of the monopole which in our case is $L-L_{\mathrm{g}}$. Factor $k$ is intuitively equal to $\sqrt{\left(\epsilon_{r}+1\right) / 2}$. However, empirical values of $k$ have been found for different substrates so that the estimates are within $10 \%$ from the measured results. The value of $k$ for the used substrate is 1.15 [13]. Evaluation of (1) results in $f_{\text {high }}=6.6 \mathrm{GHz}$ which is close to that of Antenna A (within 10\%). The lower resonant frequency is that of a quarter-wave shorted parasitic resonator, and, therefore, its average current path length shown in Figure 1 is equal to a quarter of the guided wavelength. This resonant frequency can be theoretically estimated by modifying (1) as follows (all lengths in $\mathrm{cm}$ ):

$$
f_{\text {low }}=\frac{7.2}{\left(L_{\mathrm{p} 1}+L_{\mathrm{p} 2}+0.5 \times W_{\mathrm{p} 1}+0.5 \times W_{\mathrm{p} 2}\right) \times k} \mathrm{GHz} .
$$

The lengths in the denominator of (1) are replaced with the average current path length. For the proposed antenna, evaluating (2) results in $f_{\text {low }}=2.48 \mathrm{GHz}$, which is close to the simulated results. In the same context, given the design frequencies, (1) and (2) will provide an initial estimate of the dimensions of the monopole as well as the parasitic resonator. A full-wave EM simulator can then be used to optimize these dimensions. The parametric studies conducted in the next section can aid in designing the antenna as they provide an insight into the effect of varying each parameter on the frequency response.

\section{Design and Analysis}

In this section, a number of parametric studies are conducted using a full-wave electromagnetic simulation software to investigate the effects of several geometrical design parameters on the performance of the proposed antenna. In each study, only one parameter is varied, while the rest are kept unchanged as shown in Table 1. Also, the surface current distribution and the radiation patterns at each resonance are simulated. 


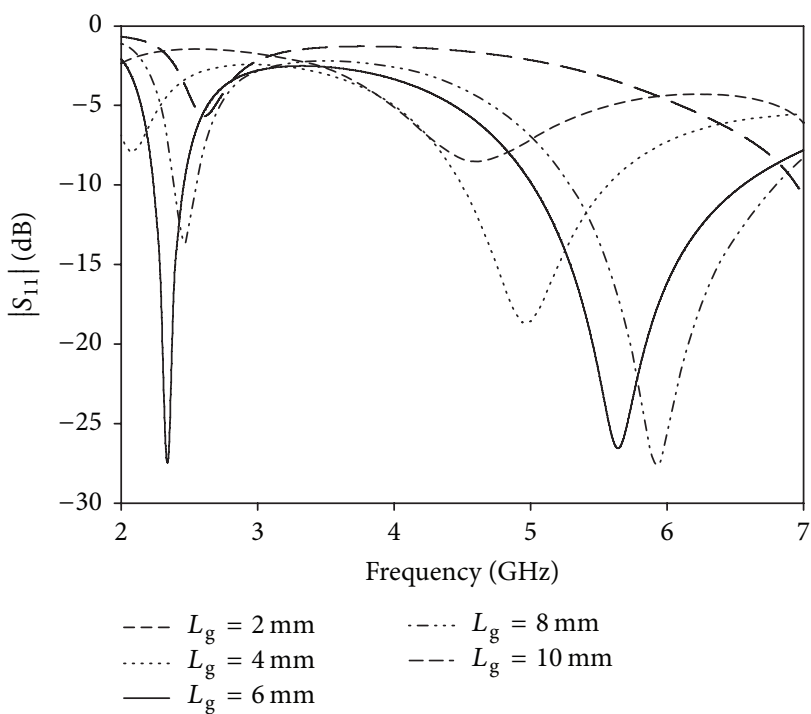

(a)

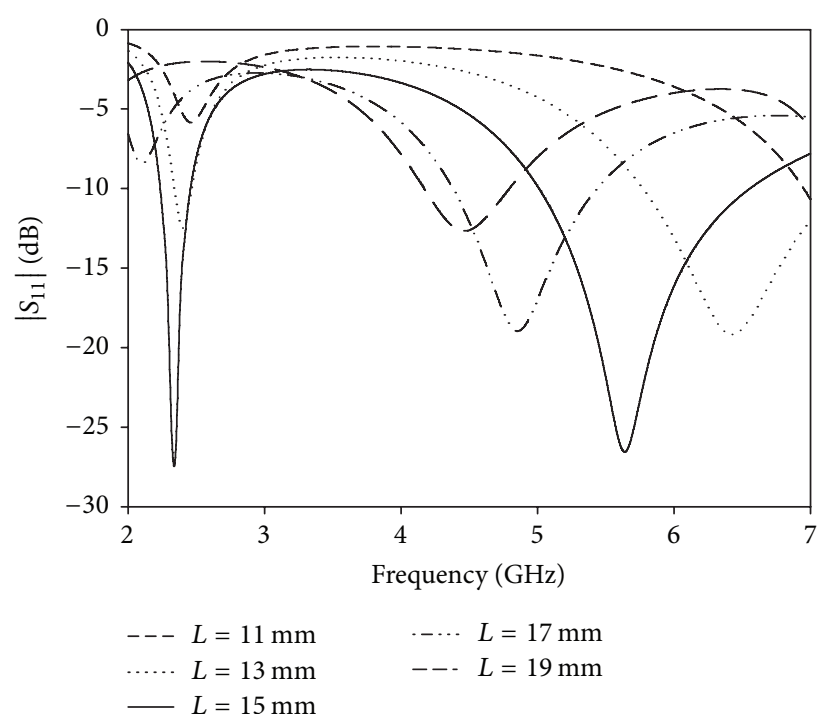

(b)

FIGURE 4: (a) The effects of varying length $L_{\mathrm{g}}$ on the reflection coefficient of the proposed antenna. Other parameters are the same as those listed in Table 1. (b) The effects of varying length $L$ on the reflection coefficient of the proposed antenna. Other parameters are the same as those listed in Table 1.
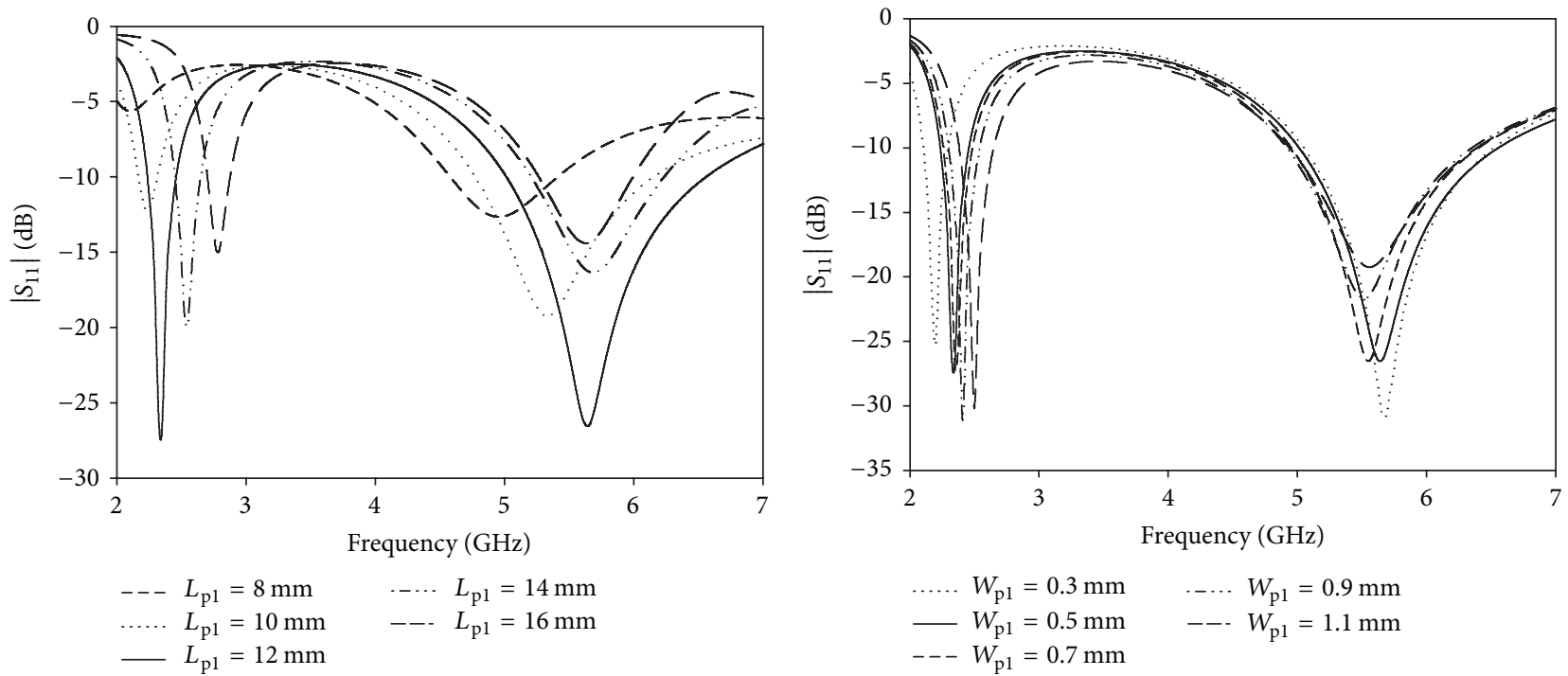

(a)
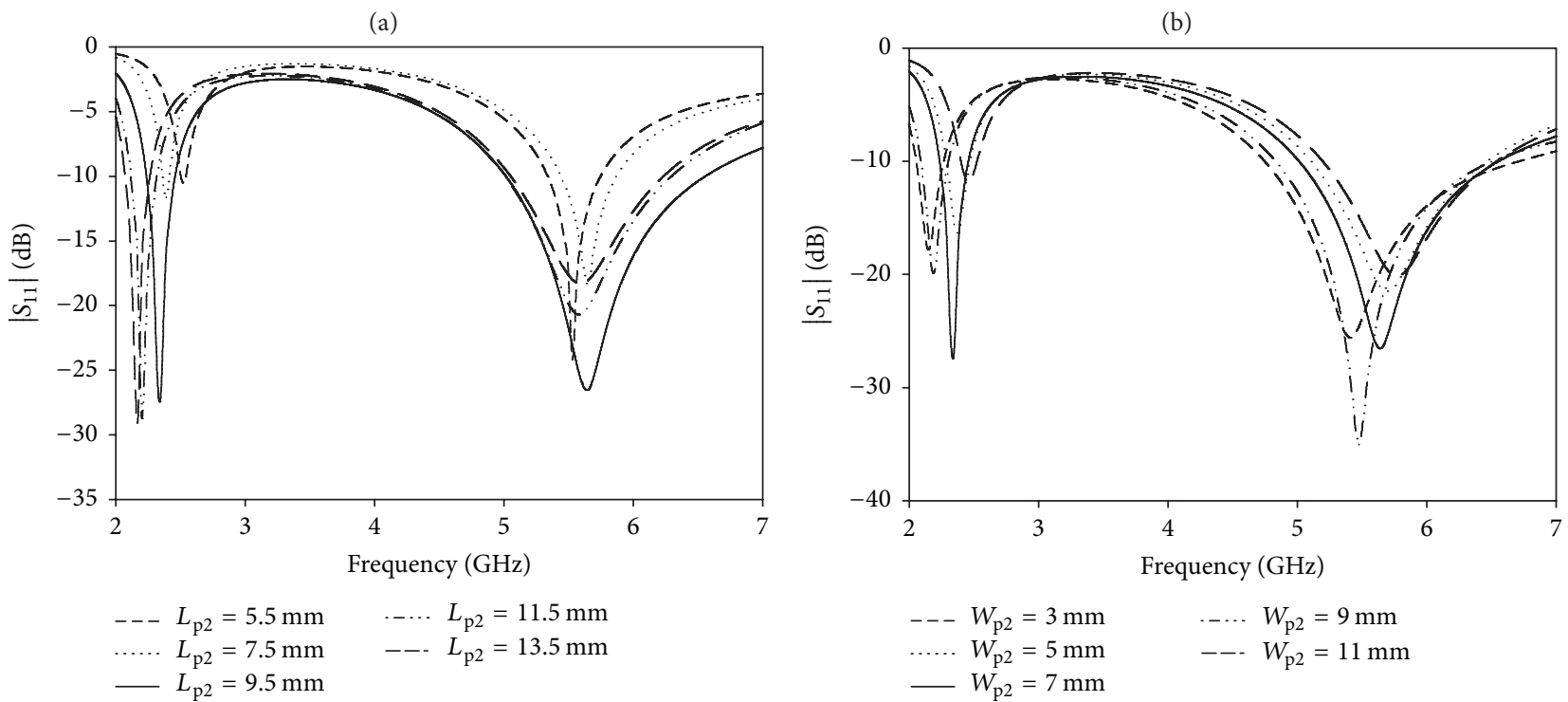

(c)

(d)

FIGURE 5: The effects of varying the four parameters of the parasitic resonator on the reflection coefficient of the proposed antenna. (a) $L_{\mathrm{p} 1}$. (b) $W_{\mathrm{p} 1}$. (c) $L_{\mathrm{p} 2}$. (d) $W_{\mathrm{p} 2}$. (In each study, the other parameters are the same as those listed in Table 1.) 


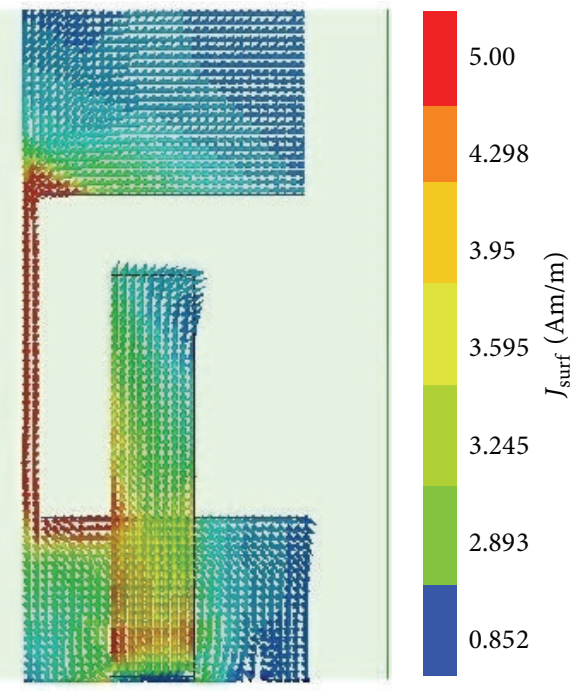

(a)

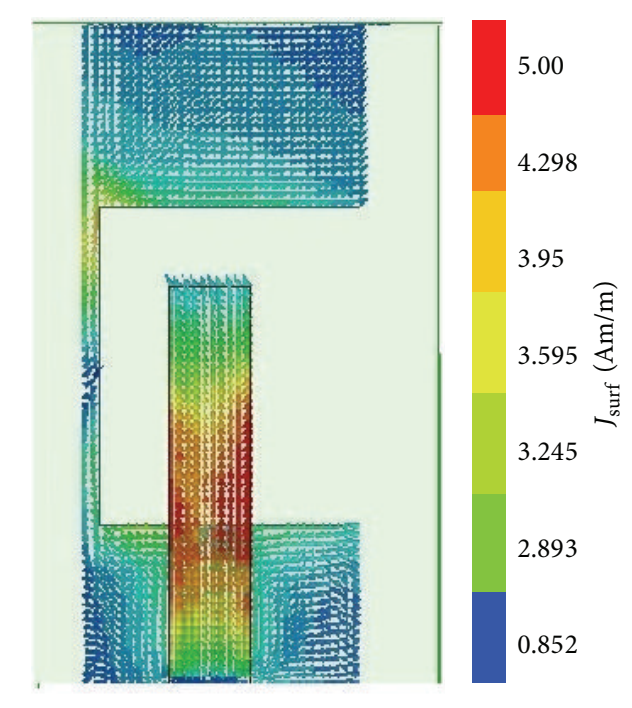

(b)

FIGURE 6: Surface current distribution of the proposed antenna at (a) the first band at $2.4 \mathrm{GHz}$ and (b) the second band at $5.6 \mathrm{GHz}$.

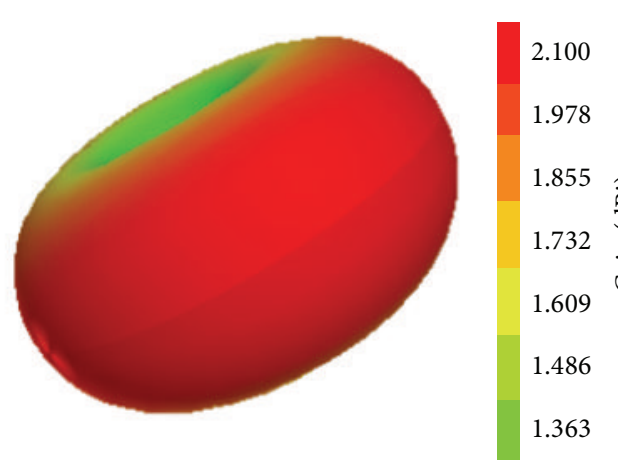

(a)

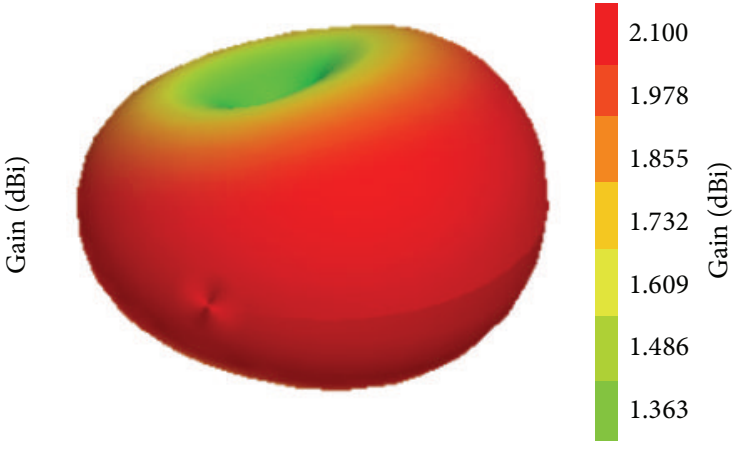

(b)

FIGURE 7: Three-dimensional radiation patterns of the proposed antenna at (a) the first band at $2.4 \mathrm{GHz}$ and (b) the second band at $5.6 \mathrm{GHz}$.

3.1. Parametric Studies. The geometrical parameters to be studied in this section are the length of the ground plane $\left(L_{\mathrm{g}}\right)$, the total length of the strip monopole $(L)$, and the four parameters of the parasitic resonator which are $L_{\mathrm{p} 1}, W_{\mathrm{p} 1}, L_{\mathrm{p} 2}$, and $W_{\mathrm{p} 2}$. These studies are conducted with a fixed ground plane width of $W_{\mathrm{g}}=10 \mathrm{~mm}$ and a monopole (and feeder) width of $W=3 \mathrm{~mm}$ so that the line impedance of the microstrip feeder remains $50 \Omega$. It should be mentioned that, in the studies, the results corresponding to the parameters listed in Table 1 (and those of the final design) are plotted using solid lines. First, the effect of the truncated ground plane length $L_{\mathrm{g}}$ is investigated as shown in Figure 4(a).

It can be seen that this parameter is of great impact on both resonances in terms of resonance frequency and impedance matching which is mainly because of the ground being truncated. This can be beneficial to the antenna design as a good performance can be achieved with a small value of $L_{\mathrm{g}}$ leading to a compact design. Afterwards, the effect of length $L$ is analyzed and the results are depicted in Figure 4(b). As expected, the second resonance is strongly affected with the variation in $L$, since it represents the resonant length of the monopole. A small shift in the lower resonant frequency along with impedance matching effects is observed, and these are attributed to the coupling between the parasitic resonator and the monopole.

The impact of the four parameters related to the parasitic resonator $\left(L_{\mathrm{p} 1}, W_{\mathrm{p} 1}, L_{\mathrm{p} 2}\right.$, and $\left.W_{\mathrm{p} 2}\right)$ is investigated as shown in Figures 5(a)-5(d). It can be observed that the four parameters have similar effects on both bands of the proposed antenna. When each parameter is varied, the first band is tuned, whereas a variation in the second bands impedance bandwidth is observed. The shift in the first band can be explained by considering the average current path in the parasitic resonator shown in Figure 1. Varying any of the four parameters results in a change in the resonators average current path length and, accordingly, its resonant frequency. On the other hand, the impedance bandwidth variation of the second band can be explained by investigating the relationship between the monopole radiator and the parasitic resonator. The horizontal strip of the parasitic resonator acts 


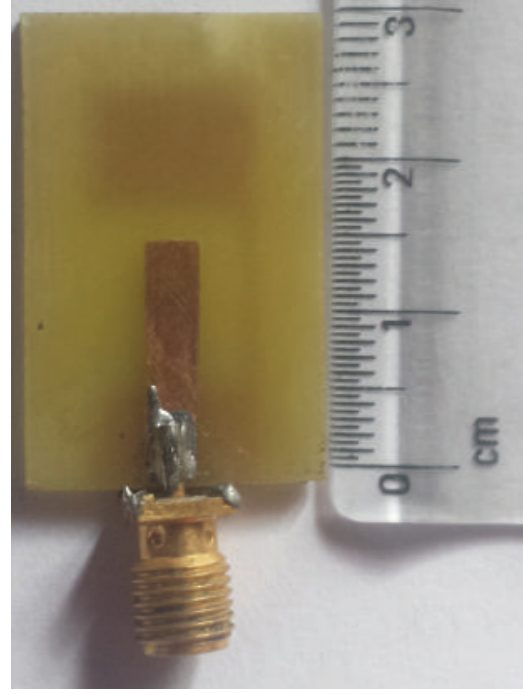

(a)

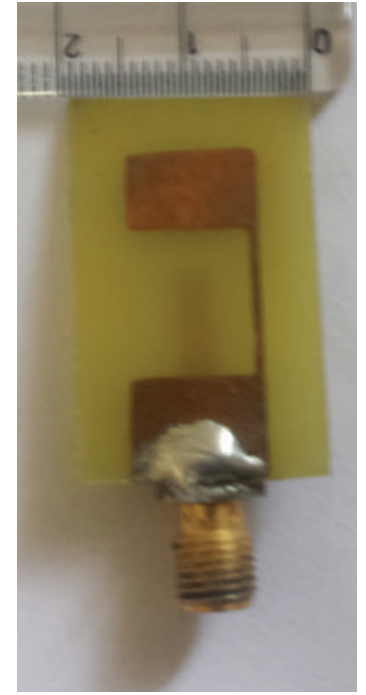

(b)

FIGURE 8: A photograph of the proposed dual-band monopole antenna. (a) Front view. (b) Back view.

as a parasitic plane for the monopole which is known to affect the impedance matching bandwidth at the monopoles operating band as in [14]. This applies to the proposed antenna as the size of the horizontal strip (determined by $W_{\mathrm{p} 1}, L_{\mathrm{p} 2}$, and $\left.W_{\mathrm{p} 2}\right)$ and its position from the monopole (determined by $L_{\mathrm{p} 1}$ ) affect the impedance bandwidth at the second band. It is worth mentioning that when the horizontal strip gets closer to the monopole, a shift in the second band is observed (see Figure 5(a)). To be more specific, the horizontal strip starts to be directly beneath the monopole (for $L_{\mathrm{p} 2}$ less than $12 \mathrm{~mm}$ ) which affects its resonance frequency.

3.2. Current Distribution and Radiation Patterns. The surface current distribution of the proposed dual-band antenna at both of its resonant frequencies is shown in Figure 6. At the lower resonant frequency, the current distribution shown in Figure 6(a) is mainly excited on the ground plane parasitic resonator with a quarter- wave variation. On the other hand, the current distribution at the higher resonant frequency, which is shown in Figure 6(b), is prominent on the monopole which is observed to be of a quarter-wave variation. The simulated three-dimensional radiation patterns of the antenna at both resonant frequencies are shown in Figure 7. It is obvious that the patterns are omnidirectional in both frequencies. It should be mentioned that, similar to conventional printed monopoles, the radiation at both bands is linearly polarized.

\section{Experimental Results}

The proposed antenna shown in Figure 1 is fabricated on the FR-4 substrate with the dimensions stated in Section 2. A photograph of the fabricated antenna is shown in Figure 8.

The measured reflection coefficient is plotted in Figure 9, where it is found to be in good agreement with its simulated counterparts. From the measured plots, the first band is

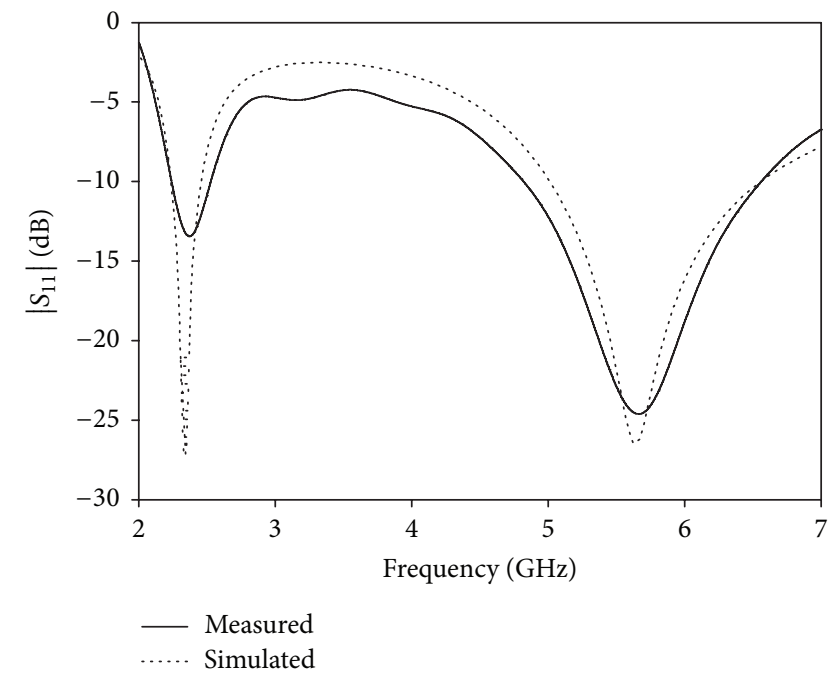

FIGURE 9: Measured and simulated reflection coefficient of the proposed dual-band monopole.

centered at $2.37 \mathrm{GHz}$ with a $-10 \mathrm{~dB}$ bandwidth of $0.3 \mathrm{GHz}$, whereas the second band is centered at $5.64 \mathrm{GHz}$ with a $-10 \mathrm{~dB}$ bandwidth of $1.6 \mathrm{GHz}$. From applications standpoint, the first band covers the $2.4 \mathrm{GHz}$ WLAN band, whereas the second band can cover both 5.2 and $5.8 \mathrm{GHz}$ WLAN bands. Also, the first band is wide enough to cover the IEEE specified PCS (Personal Communications Service) $2.4 \mathrm{GHz}$ communication band.

The measured and simulated radiation patterns of the linearly polarized antenna at the first and second bands are shown in Figures 10 and 11, respectively. It can be clearly seen from both figures that the radiation patterns of the antenna at both bands exhibit omnidirectional-like behavior (with a maximum variation of $5 \mathrm{~dB}$ ). Also, low cross-polarization 


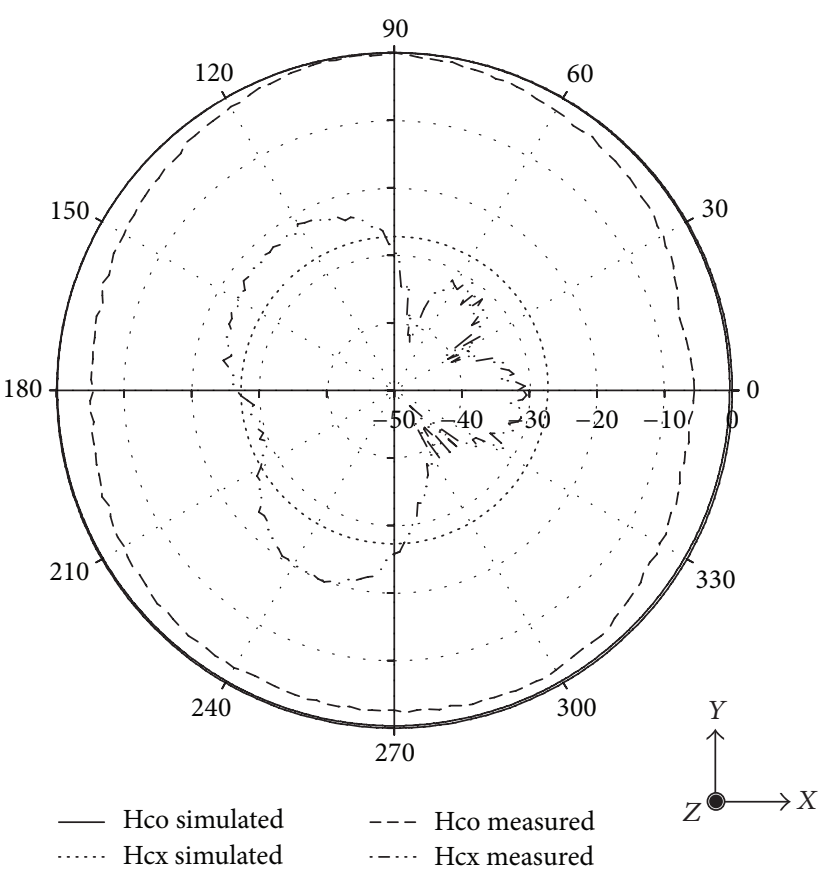

(a)

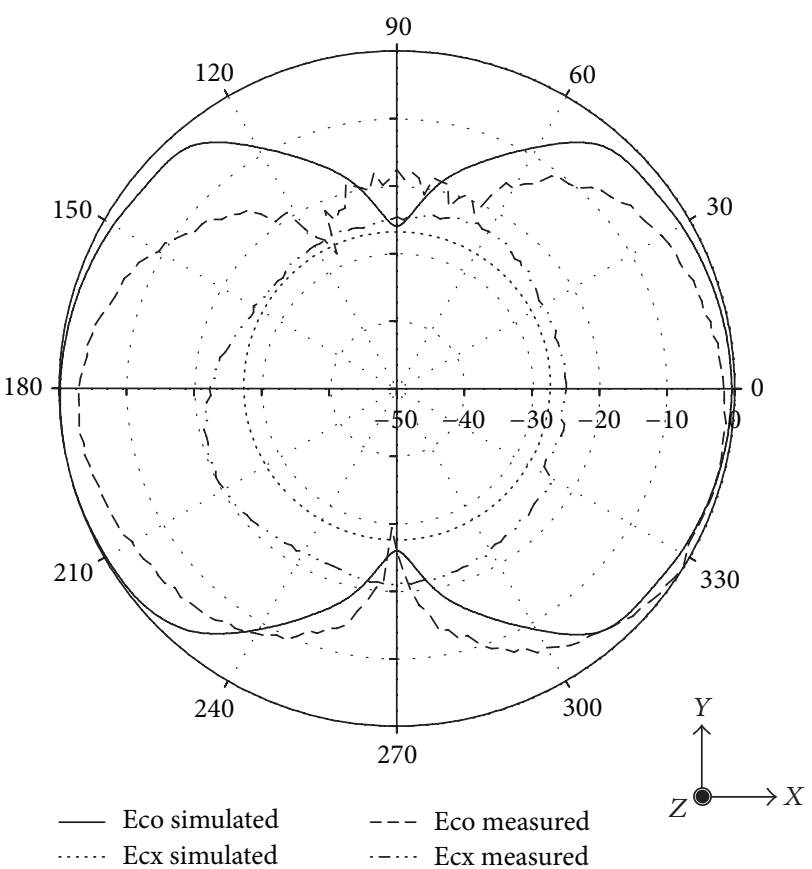

(b)

FIGURE 10: Measured and simulated radiation patterns of the antenna at the first band $(2.4 \mathrm{GHz})$. (a) H-plane. (b) E-plane.

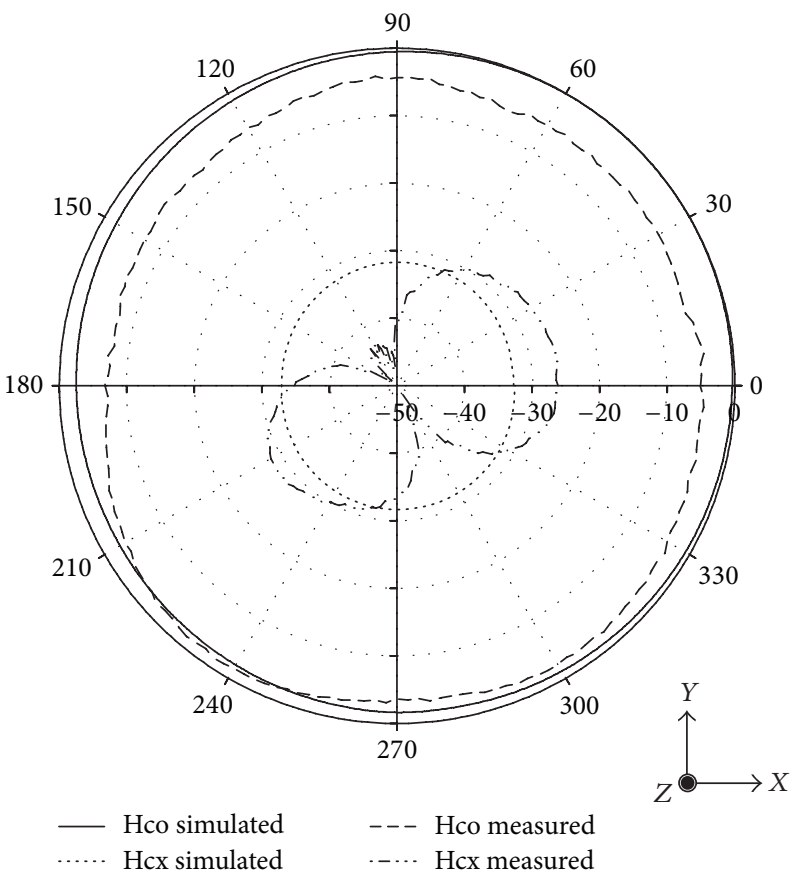

(a)

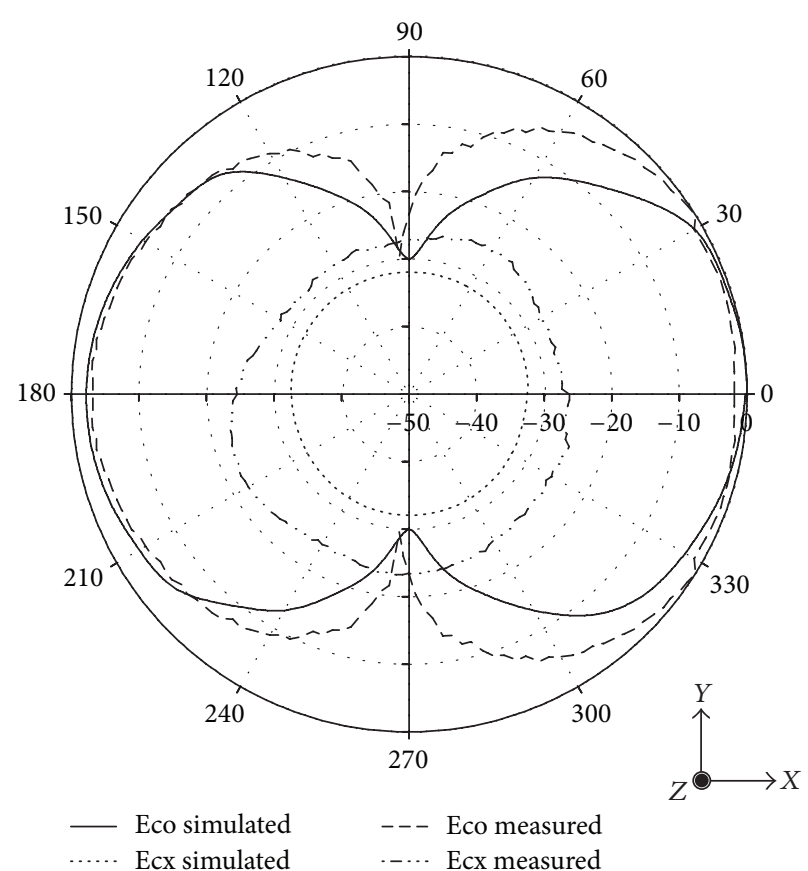

(b)

Figure 11: Measured and simulated radiation patterns of the antenna at the second band (5.8 GHz). (a) H-plane. (b) E-plane.

levels can be observed from the measured patterns. The gain of the proposed antenna has been measured at both bands of operation, and the results are shown in Figure 12(a). At the first band (around $2.4 \mathrm{GHz}$ ), the antenna has an average gain of $1.8 \mathrm{dBi}$, whereas it is $2.1 \mathrm{dBi}$ at the second band (around $5.6 \mathrm{GHz}$ ). The measured efficiency of the proposed antenna at both bands is shown in Figure 12(b). Peak efficiency of $83 \%$ and $96 \%$ is obtained in the $2.4 \mathrm{GHz}$ and $5.8 \mathrm{GHz}$ bands, respectively.

A comparison between monopole antennas loaded with parasitic resonators and the proposed antenna in terms of size, operating bands, the bandwidth, and the average peak 


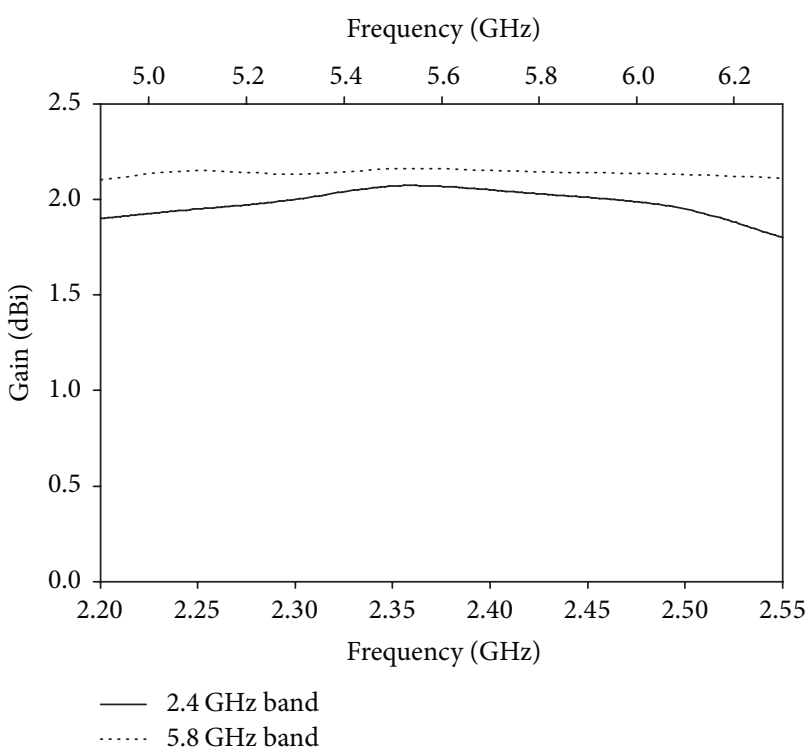

(a)

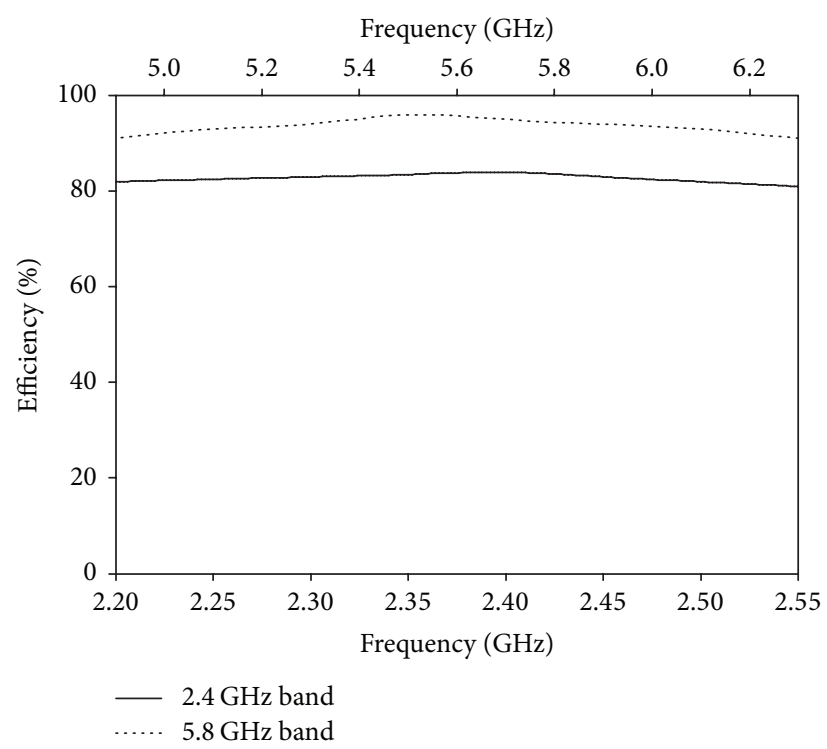

(b)

FIGURE 12: Measured radiation performance of the proposed antenna. (a) Gain. (b) Efficiency.

TABle 2: Performance comparison of the proposed antenna with other antennas in the literature.

\begin{tabular}{|c|c|c|c|c|}
\hline Reference & Size $(\mathrm{mm})^{3}$ & Operating bands $(\mathrm{GHz})$ & $\begin{array}{c}\text { Bandwidth (GHz) and } \\
\text { fractional bandwidth (\%) }\end{array}$ & Average peak gain $(\mathrm{dBi})$ \\
\hline [1] & $30 \times 30 \times 0.8$ & $3.4-7.62$ & $4.22(76)$ & 4 \\
\hline [2] & $36 \times 26 \times 1.6$ & $2.4-2.48$ and $5.15-5.35$ & $0.08(3.3)$ and $0.2(3.8)$ & 3.6 \\
\hline$[3]$ & $30 \times 20 \times 1.6$ & $2.14-2.52,2.82-3.74$, and $5.15-6.02$ & $\begin{array}{c}0.38(16.3), 0.92(28), \text { and } \\
0.87(15.6)\end{array}$ & $2.46,2.45$, and 3 \\
\hline$[4]$ & $30 \times 18 \times 1.6$ & $2.39-2.69,3.38-3.73$, and $5.0-5.99$ & $\begin{array}{c}0.3(11.8), 0.35(9.8), \text { and } \\
0.99(18)\end{array}$ & $2.52,2.37$, and 4.15 \\
\hline [5] & $37 \times 20 \times 0.508$ & $2.4-2.65,3.3-4.05$, and $5-5.98$ & $\begin{array}{c}0.25(9.9), 0.75(20.4), \text { and } \\
0.98(17.8)\end{array}$ & Not mentioned \\
\hline$[6]$ & $95 \times 56 \times 1.57$ & $0.88-0.96,1.22-1.26$, and $1.56-2.7$ & $\begin{array}{c}0.08(8.7), 0.04(3.22), \text { and } \\
1.14(53.5)\end{array}$ & $2.8,3.1$, and 3.2 \\
\hline [9] & $30 \times 25 \times 1.6$ & $2.47-2.73,3-4$, and $4.88-6.12$ & $\begin{array}{c}0.26(10), 1(28.6), \text { and } 1.24 \\
(22.5)\end{array}$ & 3.7, 3.1, and 4.8 \\
\hline$[10]$ & $50 \times 35 \times 1.6$ & $2.05-2.86$ and $5.55-6.14$ & $0.81(33)$ and $1.24(22.5)$ & 3.73 and 3.59 \\
\hline$[11]$ & $34.5 \times 18 \times 1.6$ & $2.35-2.49,3.27-3.8$, and $4.65-5.89$ & $\begin{array}{c}0.14(5.8), 0.53(15), \text { and } \\
1.24(23.5)\end{array}$ & $\begin{array}{l}2.84,2.28 \text {, and } 4.29 \text { (peak } \\
\text { gains at center frequency) }\end{array}$ \\
\hline [12] & $22 \times 28 \times 0.8$ & $2.49-2.66,3.41-3.73$, and $4.73-5.93$ & $\begin{array}{c}0.17(6.6), 0.32(9), \text { and } 1.2 \\
(22.5)\end{array}$ & $\begin{array}{c}3,4.2 \text {, and } 4.5 \text { (peak gains at } \\
\text { center frequency) }\end{array}$ \\
\hline [14] & $50 \times 35 \times 1.6$ & $0.86-0.98,1.7-2.5$, and $4.72-6.61$ & $\begin{array}{c}0.12(13), 0.8(38), \text { and } 1.9 \\
(33.4)\end{array}$ & $1.13,2.01$, and 3.74 \\
\hline Proposed antenna & $25 \times 10 \times 1.6$ & $2.22-2.55$ and $4.8-6.5$ & $0.33(13.8)$ and $1.7(3)$ & 2.2 \\
\hline
\end{tabular}

gain is given in Table 2. It is evident from Table 2 that the proposed antenna has a very compact size compared with the other antennas.

\section{Equivalent Circuit Modelling}

In this section, an R-L-C equivalent circuit model of the antenna is developed and verified with the aid of techniques presented in [15]. The equivalent circuit model of the proposed antenna is given in Figure 13. The circuit consists of two parallel R-L-C tanks along with a shunt branch. The first two tank circuits correspond to the first and second resonance, whereas the shunt branch with R3 and L3 contributes to the input impedance of the antenna.

The parameters of the tank circuit can be computed by solving a set of equations formed as follows. First, 


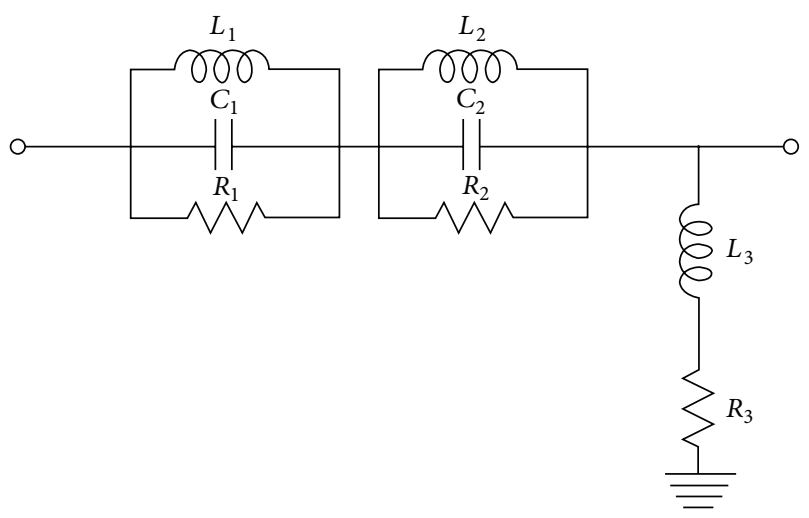

FIGURE 13: The equivalent circuit model of the dual-band antenna.

the series impedance of the circuit at any frequency $(f)$ will be

$$
\begin{aligned}
Z_{\text {Series at } f=} & \frac{1}{\sqrt{\left(C_{1} \omega-1 / L_{1} \omega\right)^{2}+1 / R_{1}^{2}}} \\
& +\frac{1}{\sqrt{\left(C_{2} \omega-1 / L_{2} \omega\right)^{2}+1 / R_{2}^{2}}},
\end{aligned}
$$

where $\omega=2 \pi f$. At the first resonance, the expression for the series impedance is reduced to

$$
Z_{\text {Series at } F 1}=R_{1}+\frac{1}{\sqrt{\left(C_{2} \omega_{1}-1 / L_{2} \omega_{1}\right)^{2}+1 / R_{2}^{2}}} .
$$

Similarly, the expression for the series impedance at the second resonance is reduced to

$$
Z_{\text {Series at } F 2}=R_{2}+\frac{1}{\sqrt{\left(C_{1} \omega_{2}-1 / L_{1} \omega_{2}\right)^{2}+1 / R_{1}^{2}}}
$$

The shunt impedance of the circuit at a frequency $f$ will be

$$
Z_{\text {Shunt at } f}=\sqrt{\left(L_{3} \omega\right)^{2}+R_{3}^{2}} \text {. }
$$

According to voltage dividing principle, the ratio of output voltage to input voltage, which is a measure of transmission coefficient, can be obtained as

$$
\frac{V_{o}}{V_{i}}=10^{\left(1-S_{11}\right) / 20}=\frac{Z_{\text {Shunt }}}{Z_{\text {Shunt }}+Z_{\text {Series }}} .
$$

There are eight parameters in the model, and, to find them, we need eight equations. These equations can be formulated by choosing eight frequencies, then substituting (3) and (6) into (7). By solving the formulated equations, all the circuit parameters can be computed. For the proposed antenna, the values of the circuit elements in the model are $L_{1}=0.32 \mathrm{nH}$, $L_{2}=5.69 \mathrm{nH}, L_{3}=0.696 \mathrm{nH}, C_{1}=14.298 \mathrm{pF}, C_{2}=14.12 \mathrm{pF}$, $R_{1}=48.4 \Omega, R_{2}=54.63 \Omega$, and $R_{3}=362.3 \Omega$. The resonant frequencies obtained from the equivalent circuit are $2.35 \mathrm{GHz}$ and $5.6 \mathrm{GHz}$ with a bandwidth of $0.24 \mathrm{GHz}$ in the first band and $1.53 \mathrm{GHz}$ in the second band. These results are in a very good agreement with the experimental result as shown in Figure 14.

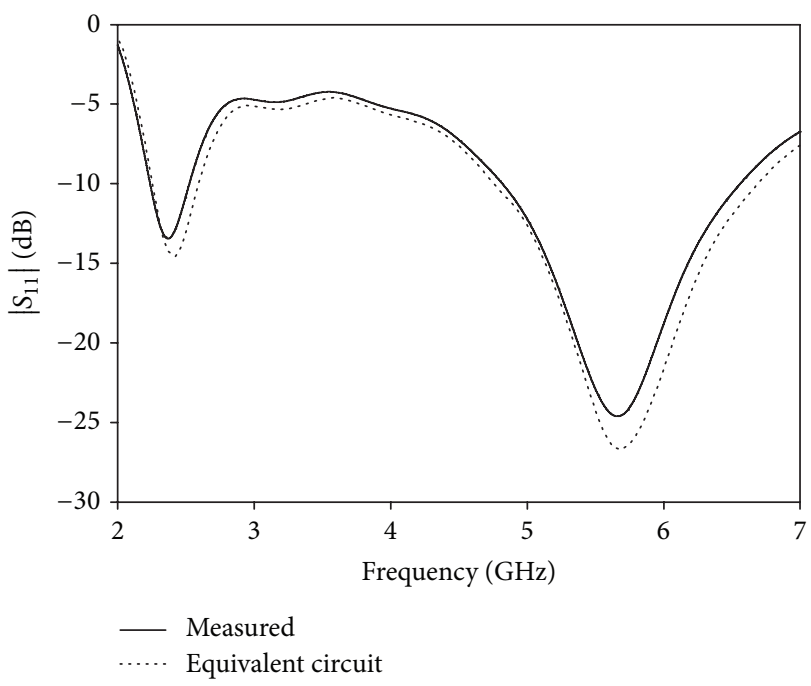

FIGURE 14: Comparison between the measured reflection coefficient and that produced by the equivalent circuit model of the proposed antenna.

\section{Conclusion}

A planar dual-band microstrip-fed monopole antenna of a simple and compact structure is presented. Besides the band excited by the monopole radiator, an additional band of operation is excited by placing a shorted inverted-L parasitic resonator on the bottom of the substrate. The parasitic resonator also improves the impedance bandwidth of the original band. The microstrip feed is a truncated ground whose dimensions can be optimized to achieve a good performance with compact size. The proposed antenna is designed to cover the 2.4/5.2-5.8 GHz bands utilized in WLAN applications. The impact of the geometrical parameters on the performance of the dual-band monopole antenna is investigated through a series of simulated parametric studies. Measured and simulated results show that the antenna operates at both bands with good impedance matching, typical monopole-like radiation patterns, and flat gain. An equivalent circuit model of the proposed antenna, which gives accurate results when compared to measurements, is presented.a

\section{Competing Interests}

The authors declare that there are no competing interests regarding the publication of this paper.

\section{References}

[1] W.-C. Liu, C.-M. Wu, and Y.-J. Tseng, "Parasitically loaded CPW-fed monopole antenna for broadband operation," IEEE Transactions on Antennas and Propagation, vol. 59, no. 6, pp. 2415-2419, 2011.

[2] K. H. Sayidmarie and T. A. Nagem, "Compact dual-band dualring printed mono-pole antennas for WLAN applications," Progress in Electromagnetics Research B, no. 43, pp. 313-331, 2012. 
[3] W.-C. Liu, C.-M. Wu, and Y. Dai, "Design of triple-frequency microstrip-fed monopole antenna using defected ground structure," IEEE Transactions on Antennas and Propagation, vol. 59, no. 7, pp. 2457-2463, 2011.

[4] S. S. Huang, J. Li, and J. Z. Zhao, "Compact CPW-fed triband antenna for WLAN/WIMAX applications," Progress in Electromagnetics Research C, vol. 49, pp. 39-45, 2014.

[5] L. Xu, Z. Y. Xin, and J. He, "A compact triple-band forkshaped antenna for WLAN/WiMAX applications," Progress in Electromagnetics Research Letters, vol. 40, pp. 61-69, 2013.

[6] A. A. Ibrahim and A. M. E. Safwat, "Microstrip-fed monopole antennas loaded with CRLH unit cells," IEEE Transactions on Antennas and Propagation, vol. 60, no. 9, pp. 4027-4036, 2012.

[7] H.-D. Chen, "Ground plane effects on the microstrip-linefed broadband sleeve monopole antennas," IET Microwaves, Antennas and Propagation, vol. 2, no. 6, pp. 601-605, 2008.

[8] H.-D. Chen, "Compact broadband microstrip-line-fed sleeve monopole antenna for DTV application and ground plane effect," IEEE Antennas and Wireless Propagation Letters, vol. 7, pp. 497-500, 2008.

[9] J. H. Lu and B. J. Huang, "Planar multi-band monopole antenna with L-shaped parasitic strip for WiMAX application," IET Electronics Letters, vol. 46, no. 10, pp. 671-672, 2010.

[10] J. R. Panda and R. S. Kshetrimayum, "A printed 2.4 ghz/5.8ghz dual-band monopole antenna with a protruding stub in the ground plane for WLAN and RFID applications," Progress in Electromagnetics Research, vol. 117, pp. 425-434, 2011.

[11] P. Xu, Z.-H. Yan, and C. Wang, "Multi-band modified forkshaped monopole antenna with dual L-shaped parasitic plane," Electronics Letters, vol. 47, no. 6, pp. 364-365, 2011.

[12] J.-H. Lu and Y.-Y. Lee, "Planar compact triple-band monopole antenna for IEEE $802.16 \mathrm{~m}$ worldwide interoperability for microwave access system," IET Microwaves, Antennas and Propagation, vol. 7, no. 13, pp. 1045-1054, 2013.

[13] K. P. Ray, "Design aspects of printed monopole antennas for ultra-wide band applications," International Journal of Antennas and Propagation, vol. 2008, Article ID 713858, 8 pages, 2008.

[14] K. Seol, J. Jung, and J. Choi, "Multi-band monopole antenna with inverted U-shaped parasitic plane," IET Electronics letters, vol. 42, no. 15, pp. 844-845, 2006.

[15] Q.-X. Chu and Y.-Y. Yang, "A compact ultrawideband antenna with $3.4 / 5.5 \mathrm{GHz}$ dual band-notched characteristics," IEEE Transactions on Antennas and Propagation, vol. 56, no. 12, pp. 3637-3644, 2008. 


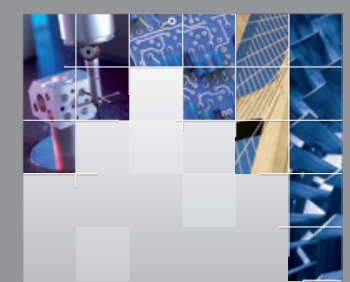

\section{Enfincering}
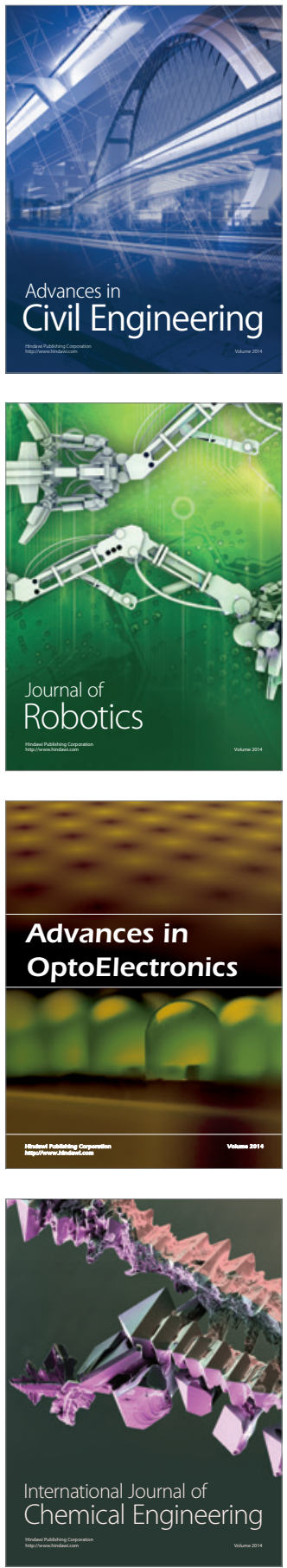

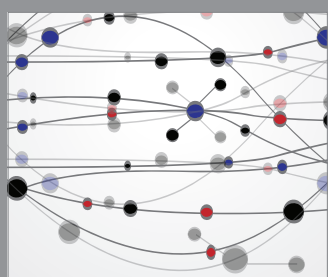

The Scientific World Journal

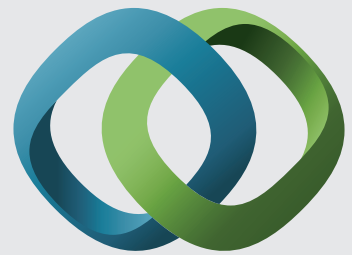

\section{Hindawi}

Submit your manuscripts at

http://www.hindawi.com
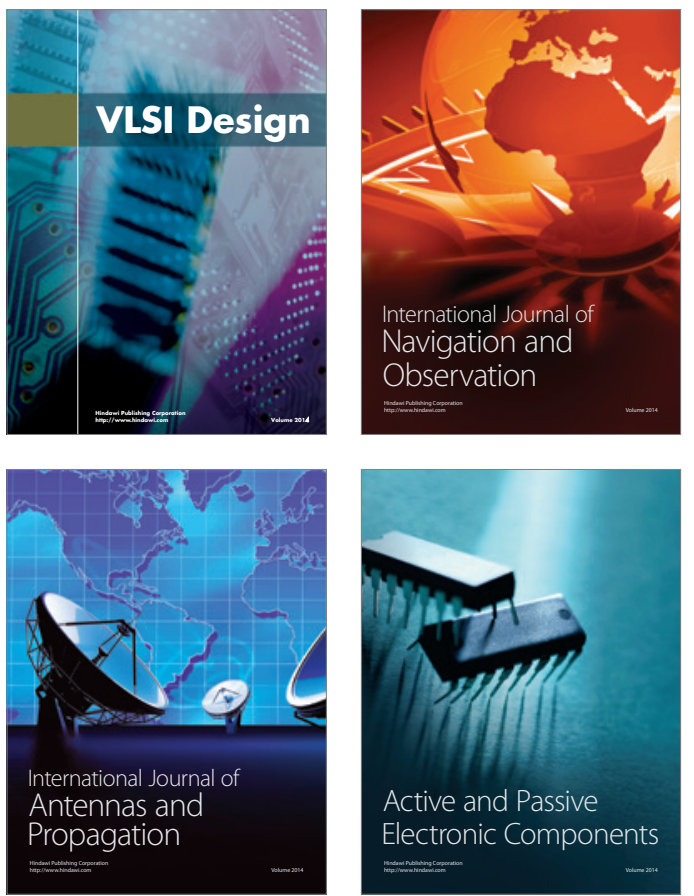
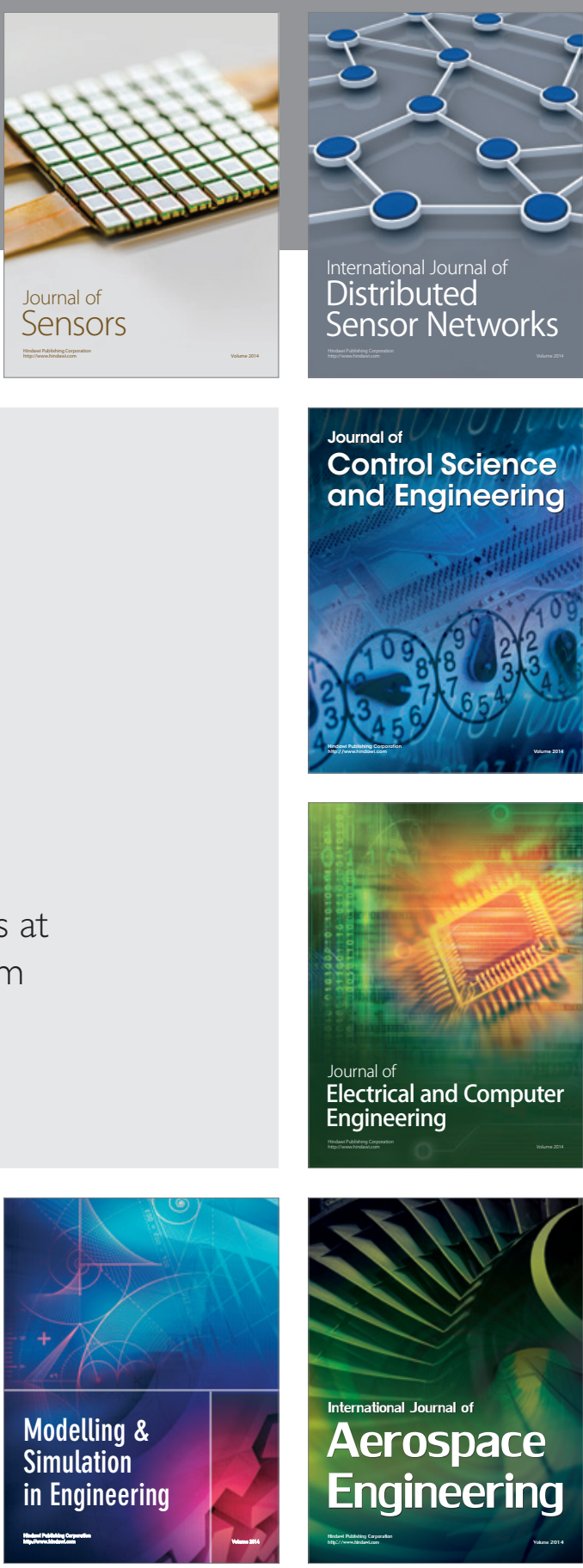

International Journal of

Distributed

Sensor Networks

Journal of

Control Science

and Engineering
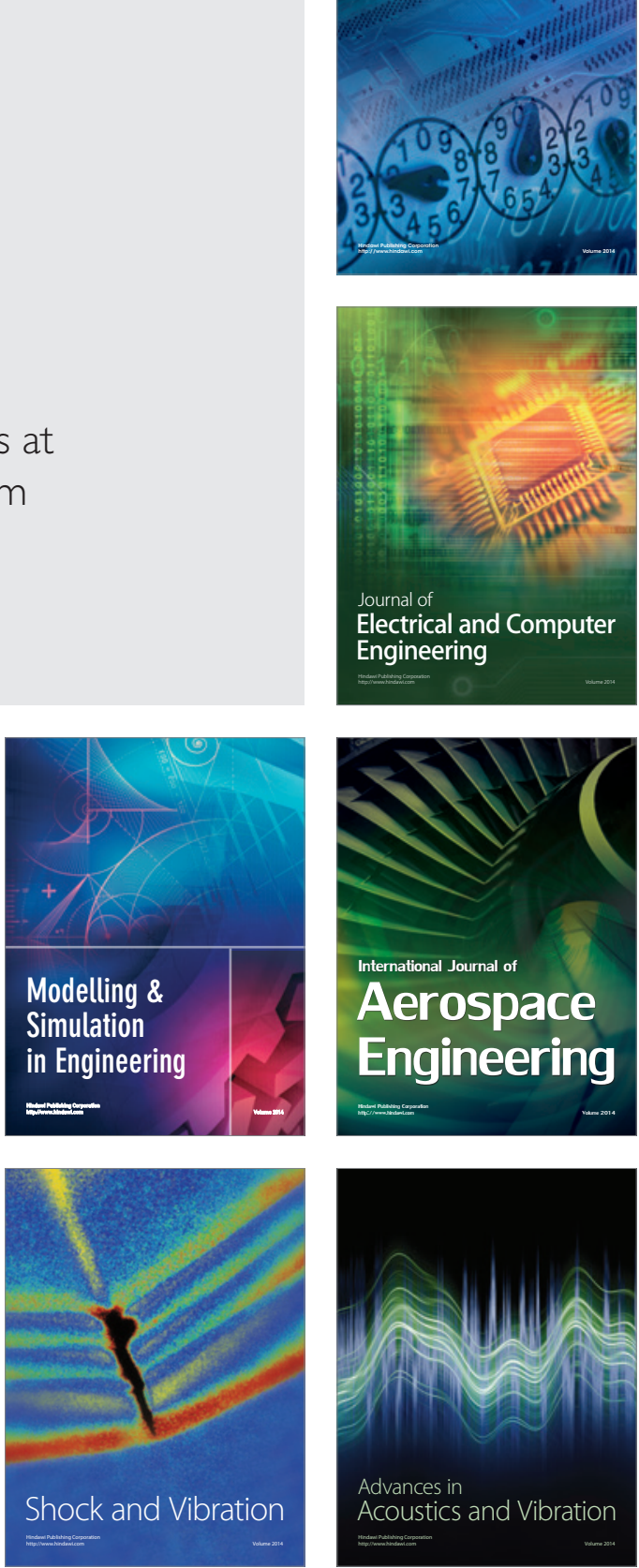